\title{
Impact of HR factors on employee attitudes: an empirical analysis of a sample of ISO14001 EMS companies in Malaysia
}

\author{
Harjeet Kaur, DBA (UniSA) (Corresponding author) \\ Senior Lecturer of Economics and Statistics \\ Department of Business Studies, HELP University College Malaysia \\ Kompleks Pejabat Damansara, Jalan Dungun, Kuala Lumpur 50490, Malaysia \\ Tel: +60320958791 ext 1311 E-mail: harjeetkjs@help.edu.my
}

Received: June 18, 2011 Accepted: June 26, $2011 \quad$ DOI: 10.5296/jpag.v1i1.739

\begin{abstract}
Empirical research addressing employee attitudes as it relates to the implementation of an EMS/ISO14001 is currently lacking. The aim of this paper is to extend previous research by proposing and testing an integrative research model which links several HR factors to employee attitudes'. The HR factors identified include management commitment, empowerment, feedback and review, and rewards. In this study employee attitudes refer to job satisfaction and organizational commitment. Four hundred and seventy two middle and lower level employees in five multiple manufacturing companies currently certified to ISO 14001 were the focus of this exploratory empirical investigation. In addition four of these companies are winners of the Malaysian Prime Minister's Hibiscus Award (PMHA), Malaysia's premier private sector environmental award for business and industry. In the final data analysis two hundred and twenty three survey responses were analyzed using SPSS version 16. The research hypotheses were assessed by the multiple linear regression analysis. The results indicate that management commitment and empowerment were positively and significantly linked to employee attitudes. In addition a significant positive relationship was observed between feedback and review, and job satisfaction. Specifically management commitment was the most pivotal HR factor in fostering employee attitudes. From the survey results, some lessons are drawn for managers in effort to maximize employee motivation for successful EMS/ISO14001 implementation. The study contributes to the growing body of literature on environmental management in newly industrialized countries such as Malaysia.
\end{abstract}

Keywords: EMS /ISO14001, HR factors, employee attitudes, job satisfaction, organizational commitment. 


\section{Introduction}

An environmental management system (EMS) provides the framework for organizations to 'systematically identify, prioritize, manage, mitigate and document the environmental aspects and impacts of its operations' (Graves 2003, p. 62). The two most frequently used guidelines for environmental management system (EMS) design and certification is the voluntary international ISO 14001 standard established by the International Organization for Standardization (ISO) and the Eco-Management and Audit Scheme (EMAS) European standard (Morrow \& Rondinelli, 2002).

Several researchers advocate that HR factors (i.e. soft factors) are particularly essential to the success of an EMS (Daily \& Huang, 2001; Daily et al., 2003, 2007; Fernandez, Junquera \& Ordiz, 2003; Govindarajulu \& Daily, 2004; Kaur, 2011; Wee \& Quazi, 2005). For example, of the seven critical factors for environmental management identified by Wee and Quazi (2005), three are human resource factors: top management commitment, employee involvement and training. Daily and Huang (2001) proposed a conceptual model emphasizing human resource factors such as top management support, environmental training, employee empowerment, teamwork and rewards systems as key elements of the implementation process of an EMS. Daily, et al. (2003, 2007) studied the impact of human resource factors on employee perception of environmental performance within a large organization currently certified to ISO 14001. Their findings suggest that management support, training, employee's psychological empowerment, teamwork, and rewards have a significant relationship to perceived environmental performance and may be significant predictors of success or failure in the implementation of an EMS.

Govindarajulu and Daily (2004, p. 365) presented a comprehensive theoretical framework for environmental performance by looking at the crucial employer and employee factors affecting environmental performance. The framework emphasizes the integration of management commitment, employee empowerment, feedback and review, and rewards as key elements for successful implementation of an ISO14001 EMS and hence enhanced environmental performance. Kaur (2011) furthers the academic work highlighted above by undertaking an empirical investigation using a sample of middle and lower level employees working in five Malaysian manufacturing companies currently certified to ISO 14001. Her findings indicate that management commitment, feedback and review, and empowerment have a significant positive relationship to perceived environmental performance. However, the relationship between rewards and perceived environmental performance was statistically insignificant.

In a study of 22 organizations in New Zealand, Stone (2000) emphasized the significant influence of corporate culture and employee attitudes on the success of cleaner production initiatives. According to Pun and Hui (2001) effective adoption and implementation of ISO 14001 must garner organization-wide support, contributions and commitment. Although support from top managers is crucial to EMS success, proactive environmental initiatives often come from middle and lower parts of the organization (Pun, Hui, Lau, Law \& Lewis, 2002). However an employee survey conducted within six environmentally committed 
companies in Europe showed that line managers were generally less supportive when managing environmental activities as compared to general business activities (Ramus \& Steger, 2000; Ramus, 2001, 2002).

Case studies conducted in seven companies in Singapore which are either ISO14001 certified or in the process of certification revealed that difficulty in securing employee commitment was a common problem (Quazi, 1999). In addition, results of a mail survey administered to thirty eight companies in Malaysia showed that ISO 14001 implementation did not motivate employees nor encouraged them to work willingly in teams (Tan, 2005). Finally Abdullah and Fuong's (2010) survey of ninety seven ISO 14001 EMS certified companies in Malaysia indicate that employees were generally opposed to the changes in the workload and procedures to follow which can be very bureaucratic and unnecessary at times.

Quality management is a similar endeavor to environmental management (see for example Daily, Bishop \& Steiner, 2003, 2007; Klassen \& McLaughlin, 1993; Curkovic, 1998; Corbett \& Cutler, 2000; Daily \& Huang, 2001). Empirical studies have shown that soft TQM affects employee work attitudes (Ooi, Bakar, Arumugam, Vellapan \& Loke, 2007; Karia \& Asaari, 2006; Boon, Arumugam \& Hwa, 2005; Karia \& Ahmad, 2000). The elements of soft TQM are essentially dimensions of human resource management (Lam 1995, 1996; Wilkinson, 1992; Rahman \& Bullock, 2005). Empirical research addressing employee attitudes as it relates to the implementation of an EMS/ISO14001 is currently lacking. The aim of this paper is to extend previous research by proposing and testing an integrative research model which links several HR factors to employee attitudes. The HR factors identified include management commitment, empowerment, feedback and review, and rewards (Govindarajulu \& Daily, 2004, p. 365; Kaur, 2011). In essence employee attitude reflects job satisfaction and the individual's commitment to the organization (Landy, et al., 1993 as cited by Karia \& Asaari 2006, p. 33). The study will benefit managers in their effort to maximize employee motivation for successful EMS/ISO14001 implementation.

\section{Review of the literature}

\subsection{Employee attitudes}

Porter, Steers, Mowday \& Boulian (1974) defined organizational commitment as a strong belief in and acceptance of the goals and values of the organization and readiness to exert considerable effort on behalf of the organization, as well as a strong desire to maintain membership in the organization. Generally employees whose needs are satisfied by an organization would likely be more committed to it (Steers, 1977). While commitment emphasizes attachment to the employing organization, including its goals and values, satisfaction emphasizes the specific task environment where an employee performs his or her duties (Mowday, Steers \& Porter, 1979).

Previous empirical studies suggest that job satisfaction is a precursor to organizational commitment. For example, using a sample of human resource professionals from large US manufacturing firms as the respondents, Green, Wu, Whitten and Medlin (2006) found that satisfaction precedes commitment. Similar results are found in different settings, including 
hospitals (Rifai, 2005; Lok \& Crawford, 2001), salespeople (Jaramillo, Mulki \& Solomon, 2006), blue-collar workers (Iverson \& Roy, 1994) and information technology (Igabarai \& Guimaraes, 1993). The theoretical reasoning and previous empirical findings demonstrate that job satisfaction has a direct positive impact on organizational commitment. Hence employees' whose needs are satisfied by an organization would likely be more committed to EMS/ISO14001 implementation.

\subsection{Management commitment}

The "management commitment" factor embodies: EMS/ISO14001, participative culture, communication of environmental goals, and environmental training (Govindarajulu \& Daily, 2004, p. 365). One of the prime prerequisites for successful implementation of any major initiative within an organization is commitment from the top. The significance of top management commitment for successful EMS/ISO 14001 implementation is well documented in the environmental literature (Daily et al., 2003, 2007; Daily \& Huang, 2001; Kitazawa \& Sarkis, 2000; O'hEocha, 2000; Rezaee \& Elam, 2000; Strachan, Sinclair \& Lal, 2003; Wee \& Quazi, 2005; Zutshi \& Sohal, 2004). Research findings in the printed circuit board manufacturing industry in Hong Kong showed that top management commitment for ISO 14000 was three times more important than appropriate environmental policy and four times more important than regular management review (Chin \& Pun, 1999).

Strachan (1997) suggests that the systems of management recommended by BS7750, EMAS and ISO 14001 must be revised and stress on mechanistic solutions should be replaced with more participatory forms of management. As companies shift to more open forms of participative management, they begin the process of empowering their employees (Mallak \& Kurstedt, 1996). Findings have shown that participation in decision making increases employee motivation, job satisfaction and organizational commitment (Scott-Ladd, Travaglione \& Marshall, 2006). The strong emphasis ISO 14001 places on training and communication as a means of realizing changes and continuous improvement can be found in paragraphs 4.4.2 and 4.4.3. The environmental programs, initiatives, and goals should be communicated frequently to all employees (Daily et al., 2003, 2007; Daily \& Huang 2001). Effective communication from the top will ensure that employees understand the importance of the EMS/ISO14001, its function, and their role in identifying and controlling environmental issues. As employees have a clear vision of what the organization wants to accomplish, they can participate more actively in the process.

The provision of environmental training and education for the workforce: (1) can facilitate cultural transformation which eventually leads to a more environmentally conscious corporate culture (Govindarajulu \& Daily, 2004; Daily \& Huang, 2001; Beard, 1996; Dechant \& Altman, 1994); (2) may change attitude and behavior among managers and employees (Sammalisto \& Brorson, 2006); (3) prepares employees' for potentially new environmental operations and assists in corrective action endeavors (Daily \& Huang, 2001); (4) is an underlying condition for employee empowerment (Kitazawa \& Sarkis, 2000); and (5) enables employees to be the source of innovative ideas in pollution prevention technology and processes (Dechant \& Altman, 1994). 
Results of an employee survey in a large semiconductor Malaysian TQM prize winning organization showed top management leadership; education and training; employee participation; customer focus; organizational culture; and teamwork have a positive effect on employees' job involvement, career satisfaction and organizational commitment respectively (Boon, Arumugam, \& Hwa, 2005).

Based on the preceding discussions, the following research hypotheses are proposed for empirical testing:

Hypothesis 1: Management commitment will have a significant positive effect on job satisfaction

Hypothesis 2: Management commitment will have a significant positive effect on organizational commitment

\subsection{Empowerment}

The "empowerment" factor embodies: horizontal organizational structure, employee involvement and teams (Govindarajulu \& Daily 2004, p. 365). Among the various definitions of empowerment, Barner (1994, p. 33) provides this definition, 'employee empowerment is defined as the transfer of power and authority from managers to lower-level employees'. In the second definition Pheng and May (1997, p. 160) describes empowerment as the 'process of enabling workers to set their own work-related goals, make decisions and solve problems within their sphere of responsibility and authority'.

Generally employees who are not empowered have less commitment for improvement than the empowered employees (Argyris, 1998). The potential benefits that can result from empowerment include increased commitment, better decisions, improved quality, more innovation, and increased job satisfaction (Yukl \& Becker, 2006). In particular employee empowerment may play an integral part in the operational and corrective action categories of the ISO 14001 (Daily \& Huang, 2001).

The traditional top-down organization inhibits employee empowerment instead a flatter, horizontal organization should be in place to encourage employee empowerment (Daily \& Huang, 2001). Remmen and Lorentzen's (2000) action research on employee participation and cleaner technology in five Danish firms showed that employee participation (employee involvement) can have a strong effect on changing working routines, affecting behavior and increasing environmental consciousness. Other studies that grant the importance of employee involvement for successful environmental management include Bansal (2005), Denton (1999), Hanna, Newman and Johnson (2000), and Shrivastava (1995).

Cross-functional teams are crucial for successfully identifying and solving waste problems that exists across departments (May \& Flannery, 1995; Daily et al. 2003, 2007). In addition green teams are used to generate ideas, enhance learning experiences, explore issues, identify conflict and focus action to enhance understanding about why, what, how, where and where to pursue the best practicable environmental options (Beard \& Rees, 2000). 
Based on the preceding discussions, the following research hypotheses are proposed for empirical testing:

Hypothesis 3: Empowerment will have a significant positive effect on job satisfaction

Hypothesis 4: Empowerment will have a significant positive effect on organizational commitment

\subsection{Feedback and review}

The "feedback and review" factor embodies: monitoring environmental performance, environmental audit and corrective action (Govindarajulu \& Daily 2004, p. 365). The strong emphasis ISO 14001 places on monitoring and measurement; nonconformance and corrective and preventive action, environmental management system audit and management review can be found in paragraphs 4.5.1, 4.5.2, 4.5.4 and 4.6 respectively. Employees use feedback to learn, develop and improve their performance (Silverman, Pogson \& Cober, 2005). Steelman and Rutkowski (2004) emphasize that meaningful feedback can be used to guide, motivate and reinforce effective behaviors and put a halt to ineffective behaviors. Contrary to expectations, many environmental management programs fail to stress the importance of feedback on environmental issues (Chinander, 2001). Informal verbal feedback in addition to formal written feedback concerning employees' impact and effectiveness on environmental improvement efforts may help motivate employees for environmental endeavours (Govindarajulu \& Daily, 2004).

ISO 14001 requires a management review process through which senior management reassesses the suitability, effectiveness, and adequacy of the environmental management system at appropriate intervals to assure continuous improvements (Morrow \& Rondinelli, 2002, p. 162). Another form of review and source of feedback is the environmental audit which may be used to communicate areas for environmental improvements to employees (Govindarajulu \& Daily, 2004; Rezaee \& Elam, 2000).

Using a sample of human service workers in three different Swedish organizations (i.e. public insurance agency, social rehabilitation center and a psychiatric hospital) as the respondents, Pousette, Jacobsson, Thylefors and Hwang (2003) found that positive and negative feedback affects job satisfaction and organizational commitment indirectly, through the mediating effect of role ambiguity. Furthermore an employee survey conducted in a governmental service for employment and vocational training in Belgium showed a positive relationship between supervisor feedback environment and employee job satisfaction, and this relationship was fully mediated by quality of leader-member exchange (Anseel \& Lievens, 2007).

Based on the preceding discussions, the following research hypotheses are proposed for empirical testing:

Hypothesis 5: Feedback and review will have a significant positive effect on job satisfaction

Hypothesis 6: Feedback and review will have a significant positive effect on organizational commitment 


\subsection{Rewards}

The "rewards" factor represents: monetary, non-monetary, recognition and praise, and customize compensation (Govindarajulu \& Daily, 2004, p. 365). Several studies grant the importance of establishing a reward systems for ensuring successful environmental management (Berrone \& Gomez-Mejia, 2009; Daily et al. 2003, 2007; O'hEocha, 2000; Ramus, 2001, 2002; Ramus \& Steger, 2000; Russo \& Harrison, 2005). In a study of eight oil and gas firms operating in the UKCS, Strachan, Sinclair and Lal (2003) discovered that rewards and recognition schemes are the main methods employed to sustain employee motivation for ISO 14001 implementation. Specifically rewards are important determinants of organizational commitment and job satisfaction (Herzberg, 1966; Steers \& Porter, 1991). Furthermore rewards reinforce empowerment and good-decision making, improving corrective and preventive measures employees initiate in the ISO14001 implementation (Daily \& Huang, 2001).

Contrary to expectations, Denton's (1999) survey on the some of the best known pollution reducing companies in the world revealed that rarely are incentives, bonuses, salaries and promotions based on how well environmental goals were met. His findings showed that employees' job appraisals rarely include an environmental category. Furthermore, Ooi, Bakar, Arumugam, Vellapan and Loke (2007) study on the impact of soft TQM practices on employees' job satisfaction in a large Malaysian semiconductor organization showed that reward and recognition was not significantly associated with improvements in employees' job satisfaction.

Managers cannot follow a 'one program fits all' approach to employee incentives (Govindarajulu \& Daily, 2004). In tailoring motivational strategies, companies need to ensure that employees' extrinsic and intrinsic needs are fulfilled. Extrinsic needs will satisfy the basic human needs, as well as social needs, which are achieved through monetary rewards and recognition. Intrinsic needs address higher levels of human needs for self-esteem, achievement and growth.

Based on the preceding discussions, the following research hypotheses are proposed for empirical testing:

Hypothesis 7: Rewards will have a significant positive effect on job satisfaction

Hypothesis 8: Rewards will have a significant positive effect on organizational commitment

\section{Methodology}

\subsection{Sample}

Initially a total of forty five companies representing various industries identified from the FMM directory and a list obtained from the Malaysian International Chamber of Commerce $\&$ Industry (MICCI) were invited to participate in the survey. Only five companies agreed to participate. Each company determined the numbers of employees that were allowed to participate in the survey. In addition, past studies provided a reference point on the number of employees and companies to be included in the research analysis. For example, Daily et al. 
(2003, 2007) examined the impact of human resource (HR) practices on employee perceptions of environmental performance. Their sample consists of 437 employees in an organization with a well-developed EMS program and ISO 14001 certification.

In the second study, Ramus and Steger (2000) and Ramus (2001) assessed whether organizational environmental policies and line management behaviors provided a good indicator of employee willingness to try eco-initiatives in six environmentally proactive organizations. The companies represented a number of industries, including chemicals, entertainment, manufacturing, medical devices, oil and retail. The survey questionnaires were sent out in four languages to middle and low level employees from diverse workforce units representing different functions, divisions and geographic locations (12 countries in Europe). A total of 353 responses were received from mid-and-low level employees (1465 surveys were distributed).

Four hundred and seventy two middle and lower level employees in five environmentally proactive manufacturing companies currently certified to ISO 14001 were the focus of this exploratory empirical investigation. Four of these companies are also winners of the Malaysian Prime Minister's Hibiscus Award (PMHA), Malaysia's premier private sector environmental award for business and industry. In terms of size, four are large while one is a small medium company. For example in Malaysia these categories are 'small' $(<50$ employees), 'medium' (50-200 employees) and 'large' (> 200 employees) (Eng \& Yusof, 2003, p.68).

\subsection{Survey}

Available and appropriate existing survey items that had been empirically tested were adapted and utilized to ensure reliability and validity. The survey items for management commitment (item number 1 to 9), employee empowerment (item number 10 to 17), feedback and review (item number 18 to 25), and rewards (item number 26 to 33) can be found in Kaur's (2011) study on the relationship between HR factors and perceived environmental performance. The scales are measured using a five-point Likert scale ( $1=$ strongly disagree, $5=$ strongly agree).

The items on organizational commitment and job satisfaction were taken directly from Edgar and Geare's (2005) study on the relationship between HRM practices and employee attitudes. Item number 34 to 39 measure organizational commitment (organizational commitment questionnaire, OCQ: Mowday, et al., 1979). Respondents are asked to indicate the extent to which they agree with each of the statements using a five-point Likert scale ranging from $1=$ strongly disagree to $5=$ strongly agree. Item number 40 to 45 measure the job satisfaction scale (Minnesota Satisfaction Questionnaire, MSQ: Weiss, et al., 1967). Respondents are asked to indicate how satisfied they are with respect to each of the statements using a five-point Likert scale ranging from $1=$ extremely dissatisfied to $5=$ extremely satisfied. Respondents are also required to provide demographic information. 


\subsection{Pilot test}

The survey was first reviewed by management representatives of ISO 14001 certified companies and two technical committee members of the Malaysian Prime Minister's Hibiscus Award (PMHA). The survey was adjusted accordingly based on their feedback. Next, eleven employees in the small and medium company reviewed the survey primarily for clarity of questions, and to comment on the length, layout as well as the time required to complete the survey. The eleven responses from the onsite survey were excluded from the final data analysis.

\subsection{Data collection procedure}

The stratified sampling approach was utilized in order to achieve heterogeneity among respondents to reduce the common survey bias (Jun, Cai \& Shin, 2006). The sub grouping criteria are organizational level and work-departments. The work departments include production, research and development $(\mathrm{R} \& \mathrm{D})$, engineering, environmental health and safety (EHS), quality assurance, operations, purchasing, marketing etc. In each of the four large companies, a staff was responsible for distributing and collecting surveys from the employee respondents. Anonymity of responses was maintained by the collection of surveys in sealed envelopes. A total of two hundred and thirty four surveys were received, producing a response rate of 49.58 percent. The eleven survey responses from the small and medium company were excluded from the final data analysis. Of the remaining two hundred and twenty three survey responses, two hundred and eleven responses are from the recipients of the Malaysian Prime Minister's Hibiscus Award (PMHA).

\subsection{Participants}

Age of participants ranged from 19 to 55, the mean age of the total employee sample was 33 years. Educational background for the respondents ranged from secondary school to the doctorate level. The average tenure was close to 7.77 years. The mean number of years on experience with current type of job was 9.5 years. The responses on the categories of age, education, tenure, and length of experience with current type of job were incomplete. Approximately 45.3 percent of the employees were Malays, 25.6 percent Chinese, 19.7 percent Indians, 9.0 percent others and 0.4 percent failed to categorize their ethnicity. 68.6 percent of the employees were male and 31.4 percent female. 15.7 percent of the survey respondents in this study consist of executives, managers and supervisors whereas 84.3 percent are staff (i.e. engineers, technicians and the majority being the production workers).

\subsection{Data Analysis}

The data are analyzed using SPSS version 16. The constructs were subject to appropriate statistical tests to establish reliability and validity, consistent with the methods adopted by Wee and Quazi (2005) in the field of environmental management. The research hypotheses were assessed by the multiple linear regression analysis. 


\section{Results}

\subsection{Reliability assessment and item analysis}

Internal consistency analysis was carried out to measure the reliability of the items under each scale using Cronbach alpha. During the initial analysis, item number 8, 10, 17, 25, 26, 29 and 37 were dropped to improve reliability. After assessing reliability, detailed item analysis was carried out by adopting Nunnally's (1978) method for proper assignment of items to each factor.

In the item analysis, item number 6 showed almost a constant correlation across the management commitment $(\mathrm{r}=0.680)$ and empowerment $(\mathrm{r}=0.642)$ constructs. Hence item 6 was then dropped. Both the item analysis and reliability tests were performed again without item number 6. After the deletion of item number 6, the remaining items had shown high correlations with the scale score that they were assigned to, for example, the range of correlation coefficient for management commitment ranged from 0.574 to 0.753 , for empowerment 0.651 to 0.762 , for rewards 0.631 to 0.769 , for feedback and review 0.610 to 0.772 , for organizational commitment 0.721 to 0.788 , and job satisfaction 0.739 to 0.805 . It can be concluded that the remaining items had been correctly assigned to the scales, because the highest correlations were found in the scales to which they had been assigned.

Table 1 provides the final summary of items and measures of reliability of each construct. Overall the alpha values demonstrate that the constructs have relatively high scores of reliability as the minimum advisable alpha level for established scales is 0.70 (Nunnally, 1978).

Table 1: Final summary of items and measures of reliability

\begin{tabular}{lcccc}
\hline Construct & $\begin{array}{c}\text { Original items } \\
\text { (by item number) }\end{array}$ & $\begin{array}{c}\text { Items deleted } \\
\text { (item number) }\end{array}$ & $\begin{array}{c}\text { Remaining } \\
\text { number of items }\end{array}$ & $\begin{array}{r}\text { Cronbach } \\
\text { alpha }\end{array}$ \\
\hline 1. Management commitment & $1-9$ & 6,8 & 7 & 0.811 \\
2. Empowerment & $10-17$ & 10,17 & 6 & 0.795 \\
3. Feedback and review & $18-25$ & 25 & 7 & 0.810 \\
4. Rewards & $26-33$ & 26,29 & 6 & 0.781 \\
5. Organizational commitment & $34-39$ & 37 & 5 & 0.811 \\
6. Job satisfaction & $40-45$ & None & 6 & 0.867 \\
\hline
\end{tabular}




\subsection{Correlation analysis}

The correlation matrix in Table 2 indicate that the paired correlations among the independent variables are all less than 0.80 , hence multicollinearity is not a concern (Bryman \& Cramer, 1999).

Table 2: Descriptive statistics and correlation coefficients between HR factors

\begin{tabular}{lclllll}
\hline Constructs & Mean & SD & 1 & 2 & 3 & 4 \\
\hline & & & & & & \\
1. Management commitment & 3.58 & 0.56 & 1 & & & \\
2. Empowerment & 3.38 & 0.63 & $0.760^{*}$ & 1 & & \\
3. Feedback and Review & 3.41 & 0.54 & $0.744^{*}$ & $0.702^{*}$ & 1 & \\
4. Rewards & 3.00 & 0.66 & $0.690^{*}$ & $0.693^{*}$ & $0.606^{*}$ & 1 \\
\hline
\end{tabular}

*Correlation is significant at the 0.01 level (2-tailed)

The correlation for mean scale scores shown in Table 3 indicates that the HR factors are positively and moderately correlated with organizational commitment: management commitment $(\mathrm{r}=0.486, \mathrm{p}<0.01)$, empowerment $(\mathrm{r}=0.454, \mathrm{p}<0.01)$, feedback and review $(\mathrm{r}=0.398, \mathrm{p}<0.01)$ and rewards $(\mathrm{r}=0.346, \mathrm{p}<0.01)$. In addition, the HR factors are positively and moderately correlated with job satisfaction: management commitment $(\mathrm{r}=$ 0.537, $\mathrm{p}<0.01)$, empowerment $(\mathrm{r}=0.521, \mathrm{p}<0.01)$, feedback and review $(\mathrm{r}=0.518, \mathrm{p}<$ $0.01)$ and rewards $(\mathrm{r}=0.415, \mathrm{p}<0.01)$. The results suggest a significant positive relationship exists between the HR factors and employee attitudes. The strong significant positive correlation between job satisfaction and organizational commitment $(r=0.693, p<0.01)$ suggests that employees' whose needs are satisfied by an organization would likely be more committed to ISO14001 implementation.

Table 3: Correlations for mean scale scores

\begin{tabular}{lcc}
\hline Exogenous scale & $\begin{array}{c}\text { Organizational } \\
\text { commitment }\end{array}$ & Job satisfaction \\
\hline Management commitment & $0.486^{*}$ & $0.537^{*}$ \\
Empowerment & $0.454^{*}$ & $0.521^{*}$ \\
Rewards & $0.346^{*}$ & $0.415^{*}$ \\
Feedback and review & $0.398^{*}$ & $0.518^{*}$ \\
Organizational commitment & - & $0.693^{*}$ \\
Job satisfaction & $0.693^{*}$ & - \\
\hline
\end{tabular}

* Correlation is significant at the 0.01 level (2-tailed). 


\subsection{Validity assessment}

Content validity is not evaluated numerically, rather it is subjectively judged by the researchers (Wee \& Quazi, 2005). In an effort to ensure content validity available and appropriate existing measurement items that had been empirically tested were adapted and utilized whenever possible. Moreover the survey was reviewed by management representatives of ISO 14001 certified companies and two technical committee members of the Malaysian Prime Minister's Hibiscus Award.

Criterion related validity refers to the extent to which a measuring instrument is related to an independent measure of the relevant criterion (Wee \& Quazi, 2005). The HR factors will have high criterion related validity if these measures (collectively) are highly and positively correlated with the job satisfaction and organizational commitment measures. Criterion validity was assessed using two methods. In the first method, the correlations between independent scale scores and dependent scale scores were considered. The bivariate correlations shown in Table 3 demonstrate legitimate criterion validity with all values exceeding the acceptable threshold of 0.30 (Grandzol \& Gershon, 1998). In the second method, the multiple correlation coefficient, R was examined (Quazi, Khoo \& Wong, 2001; Wee \& Quazi, 2005). The multiple R correlation coefficient computed for the HR factors and organizational commitment is 0.504 (shown in Table 5) and 0.579 (shown in Table 6) for the HR factors and job satisfaction. The results suggest that the four HR factors have a reasonably moderate degree of criterion validity when taken together.

A measure has construct validity if it measures the theoretical construct that it is designed to measure (Wee \& Quazi, 2005). Each scale is factor analyzed separately using the principal components factor analysis with orthogonal rotation using the Varimax method (Geralis \& Terziovski, 2003; Wee \& Quazi, 2005). A total of six analyses were carried out. According to Guadagnoli and Velicer (1988 cited in Liang, Li, \& Kim, 2004, p. 107-108) the most important aspect leading to factor stability is the absolute magnitude of the loading and absolute sample size. Guadagnoli and Velicer suggest that factors with around 10 loadings of at least 0.40 are reliable as long as sample size is greater than 150 . With a sample size of 223, all factors loaded acceptably well with factors loadings in the $0.531-0.806$ range. Moreover, items with factor loading 0.50 or greater are considered practically significant (Hair, Anderson, Tatham \& Black, 1998). The Kaiser-Meyer-Olkin (KMO) measure of sampling adequacy test results shows factors ranging from 0.799 to 0.871 , which is much above the suggested minimum standard of 0.6 required running factor analysis (Coakes, 2005). A single component was extracted for each of the construct with the eigenvalues ranging from 2.858 to 3.616, thus establishing unidimensionality. The results of factor analysis are summarized in Table 4. 
Table 4: Summary of factors analysis

\begin{tabular}{lcccc}
\hline Construct & KMO & Item loading range & Eigenvalue & $\begin{array}{c}\text { \% variance } \\
\text { explained }\end{array}$ \\
\hline & & & & \\
Organizational commitment & 0.799 & $0.714-0.800$ & 2.858 & 57.159 \\
Job satisfaction & 0.871 & $0.741-0.806$ & 3.616 & 60.271 \\
Management commitment & 0.863 & $0.531-0.767$ & 3.321 & 47.447 \\
Empowerment & 0.849 & $0.655-0.763$ & 2.974 & 49.561 \\
Rewards & 0.817 & $0.617-0.789$ & 2.879 & 47.976 \\
Feedback and review & 0.839 & $0.621-0.776$ & 3.278 & 46.822 \\
\hline
\end{tabular}

\subsection{Regression analysis}

With reliability and validity of the constructs established, the mean values were calculated from the remaining variables to provide estimates for each construct in the multiple linear regression analysis. The result of the regression analysis with organizational commitment as the dependent variable is summarized in Table 5.

Table 5: Test results of regression analysis with organizational commitment as predictor

\begin{tabular}{|c|c|c|c|c|}
\hline Dependent variable & Organizational commitment & & & \\
\hline Multiple R & 0.504 & & & \\
\hline $\mathrm{R}$ - square & 0.254 & & & \\
\hline Adjusted R - square & 0.241 & & & \\
\hline Standard error & 0.554 & & & \\
\hline Durbin Watson & 1.927 & & & \\
\hline Analysis of variance & $d f$ & $\begin{array}{l}\text { Sum of } \\
\text { squares }\end{array}$ & $\begin{array}{l}\text { Mean } \\
\text { square }\end{array}$ & \\
\hline Regression & 4 & 22.786 & 5.696 & \\
\hline Residual & 218 & 66.849 & 0.307 & \\
\hline $\mathrm{F}=18.577$ & Significant $F=0.000$ & & & \\
\hline Variables & Standardized Beta & $T$ & Sig. & VIF \\
\hline Management commitment & 0.339 & 3.218 & 0.001 & 3.245 \\
\hline Empowerment & 0.212 & 2.120 & 0.035 & 2.922 \\
\hline Rewards & -0.053 & -.610 & 0.543 & 2.207 \\
\hline Feedback and review & 0.029 & .318 & 0.751 & 2.506 \\
\hline
\end{tabular}


The multiple $\mathrm{R}$ value of 0.504 indicates a moderate positive relationship between the variables and the R squared (0.254) means that the HR factors account for 25.4 percent of the variance in organizational commitment $\left(\mathrm{F}_{4}, 218=18.577 ; \mathrm{p}<0.000\right)$. In order to judge the magnitude effects in this study, Cohen's rule for effects sizes is consulted. According to Cohen (1998 cited in Ooi, Arumugam, Teh \& Chong, 2008, p. 919), $\mathrm{R}^{2}$ between 1.0 and 5.9 percent is considered as small, between 5.9 and 13.8 percent is medium, and above 13.8 percent is large. The effect size for this study is large as the $\mathrm{R}$ squared value is 25.4 percent.

The VIF coefficients are within 2.207-3.245 range which does not exceed the acceptable threshold of ten, minimizing concerns about multicollinearity (Hair et al., 1998). A test of autocorrelation was also generated. The Durbin-Watson $\mathrm{d}$ statistic of 1.927 is within the 1.50 - 2.50 range (Hair et al., 1998), hence minimizing concerns about autocorrelation in the regression model.

The standardized beta estimates were significantly greater than zero for management commitment $(\beta=0.339, \mathrm{p}<0.05)$ and empowerment $(\beta=0.212, \mathrm{p}<0.05)$. The statistical results demonstrate support for Hypothesis 2 and Hypothesis 4. The parameter estimate for feedback and review, and rewards were not significant at the 0.05 level. Therefore the results did not provide sufficient empirical support for Hypothesis 6 and Hypothesis 8.

Table 6 summarizes the results of the regression analysis of which job satisfaction was regressed on the four HR factors. The multiple $\mathrm{R}$ value of 0.579 indicates a moderate positive relationship between the HR factors and job satisfaction. The $\mathrm{R}$ squared $(0.336)$ indicates that the four HR factors account for 33.6 percent of the variance in job satisfaction variable $\left(\mathrm{F}_{4}\right.$, $218=27.535 ; \mathrm{p}<0.000$ ). The effect size for this study is large as the $\mathrm{R}$ squared value is 33.6 percent. The VIF values and the Durbin Watson d statistics of 1.813 suggest that concerns about multicollinearity and autocorrelation were minimized in the regression model. 
Table 6: Test results of regression analysis with job satisfaction as predictor

\begin{tabular}{|c|c|c|c|c|}
\hline Dependent variable & Job satisfaction & & & \\
\hline Multiple R & 0.579 & & & \\
\hline $\mathrm{R}$ - square & 0.336 & & & \\
\hline Adjusted R - square & 0.323 & & & \\
\hline Standard error & 0.583 & & & \\
\hline Durbin Watson & 1.813 & & & \\
\hline Analysis of variance & $d f$ & $\begin{array}{l}\text { Sum of } \\
\text { squares }\end{array}$ & $\begin{array}{c}\text { Mean } \\
\text { square }\end{array}$ & \\
\hline Regression & 4 & 37.404 & 9.351 & \\
\hline Residual & 218 & 74.035 & 0.340 & \\
\hline $\mathrm{F}=27.535$ & Significant $F=0.000$ & & & \\
\hline Variables & Standardized Beta & $T$ & Sig. & $V I F$ \\
\hline Management commitment & 0.238 & 2.389 & 0.018 & 3.245 \\
\hline Empowerment & 0.210 & 2.224 & 0.027 & 2.922 \\
\hline Rewards & -0.020 & -0.239 & 0.811 & 2.207 \\
\hline Feedback and review & 0.206 & 2.358 & 0.019 & 2.506 \\
\hline
\end{tabular}

The standardized beta estimates are significantly greater than zero for management commitment $(\beta=0.238, p<0.05)$, empowerment $(\beta=0.210, p<0.05)$ and feedback and review $(\beta=0.206, \mathrm{p}<0.05)$. The statistical results demonstrate support for Hypothesis 1 , Hypothesis 3 and Hypothesis 5 respectively. The parameter estimate for rewards was not significant at the 0.05 level therefore Hypothesis 7 was not supported.

\section{Discussion}

This paper proposed and tested a HR factors model linking employee attitudes. The HR factors include management commitment, empowerment, feedback and review, and rewards. The results indicate that the HR factors were positively and significantly correlated with employee attitudes. The strong significant positive correlation between job satisfaction and organizational commitment suggest that employees' whose needs are satisfied by an organization would likely be more committed to EMS/ISO14001 implementation. Overall, the HR factors model explained 33.6 percent of the variance in job satisfaction and 25.4 percent of the variance in organizational commitment respectively. The results are noteworthy because they suggest that a significant relationship exists between the HR factors (i.e. soft factors) and employee attitudes.

The results of the regression analysis support the link between management commitment and 
employee attitudes. On the basis of the magnitudes of the corresponding standardized beta coefficients, management commitment is the most pivotal HR factor in fostering employee attitudes. The findings of this study supports research on TQM emphasizing the significance of top management leadership, education and training, employee participation, organizational culture and teamwork for enhancing employees' organizational commitment (Boon et al., 2005). One of the prime prerequisites for successful implementation of any major initiative within an organization is commitment from the top. If employees perceive total commitment from the top, they are more accepting of and committed towards the new processes and changes associated with EMS/ISO 14001 implementation. Therefore it is essential that management commitment is achieved and maintained throughout the EMS/ISO14001 process for it to be successful. Managers in companies with an EMS/ISO14001 should promote a more participative culture and stress on the importance of effective communication. Furthermore they should ensure that employees are equipped with adequate environmental training and education.

The results of the study indicate a significant positive link between empowerment and employee attitudes. The results are supported by Yukl and Becker's (2006) findings signifying the importance of empowerment in fostering commitment and job satisfaction. Essentially when employees are empowered they become an integral part of the EMS/ISO14001 system and hence will be willing to commit themselves to the organizations environmental goals. Specifically empowerment may play an integral part in the operational and corrective action categories of the ISO 14001 (Daily \& Huang, 2001). Hence managers in companies with an EMS/ISO14001 should have horizontal organizational structures in place and be high users of employee involvement practices and green teams.

The results of this study indicate a direct positive relationship between feedback and review, and job satisfaction. However the feedback and review to organizational commitment link was not empirically supported. The results support the contention by Chinander (2001) that many environmental management programs fail to stress the importance of feedback on environmental issues. Essentially employees will be more committed if they are constantly provided feedback regarding their performance and progress toward other valued goals. Managers in companies with an EMS/ISO14001 should be aware of the importance of communicating to employees' feedback on their work performance as well as the results of the management review and environmental audit report.

In general the literature suggests that rewards are important determinants of organizational commitment and job satisfaction (Herzberg, 1966; Steers \& Porter, 1991). However, the results of this study did not provide sufficient statistical support for the rewards and employee attitudes link. The results are partially supported by Ooi et. al's (2007) findings which showed that reward and recognition was not significantly associated with employees' job satisfaction. The estimated standardized beta estimates, $\beta$ for the rewards construct is opposite from what is expected with $\beta=-0.020$ (with job satisfaction as predictor) and $\beta=-$ 0.053 (with organizational commitment as predictor). Further conceptual work followed by empirical research is required in order to determine in greater detail the role of rewards in implementing and EMS/ISO14001 and subsequent employee attitudes. 


\section{Conclusion}

The results of this exploratory study indicate management commitment and empowerment were positively and significantly linked to employee attitudes. In addition a significant positive relationship was observed between feedback and review, and job satisfaction. Management commitment is the most pivotal HR factor in fostering employee attitudes. The study contributes to the growing body of literature on environmental management in newly industrialized countries such as Malaysia.

\subsection{Research limitations}

This study has some limitations which must be considered for future research. This is a correlational cross sectional study and therefore causality can only be inferred. One needs to collect time-series data to test causal relationships. Furthermore data collection at a single point in time does not allow for changes in perception and attitudes over time as compared to longitudinal studies. For these reasons a longitudinal study is recommended. Second, the generalizability of the findings is debatable as the five companies surveyed had fully developed ISO14001 programs, and four are recipients of the Prime Minister's Hibiscus Award (PMHA). Additional studies are needed to confirm these results. Third, because only self report survey was used to collect data in this study, it is possible that a mono-method bias is present. Fourth, the findings are based on the self report survey data which may be affected by response biases.

\subsection{Directions for future research}

Future research may consider combining the self report survey methodology with structured personal interviews to triangulate the findings. Specifically top management representatives, environmental and line managers may be interviewed to elicit information pertaining to human resource management practices and employees' attitudes towards the EMS/ISO 14001 implementation. Another interesting avenue for future research is to examine the complex relationship between the HR factors, employee attitudes and environmental performance.

\section{References}

Abdullah, H. \& Fuong, C.C. (2010). The Implementation of ISO14001 Environmental Management System in Manufacturing Firms in Malaysia. Asian Social Sciences, 6(3), 100-107.

Argyris, C. (1998). Empowerment: the emperor's new clothes. Harvard Business Review, 76(3), 98-105.

Anseel, F. \& Lievens, F. (2007). The long-term impact of the feedback environment on job satisfaction: A field study in a Belgian context. Applied Psychology: An International Review, 56(2), 254-266.

Bansal, P. (2005). Evolving sustainability: A longitudinal study of corporate sustainable development. Strategic Management Journal, 26(3), 197-218.

Barner, R. (1994). Enablement: the key to empowerment. Training \& Development, 48(6), 
$33-36$.

Beard, C. (1996). Environmental training: emerging products. Industrial and Commercial Training, 28(5), 18-23.

Beard, C. \& Rees, S. (2000). Green teams and the management of environmental change in a UK county council. Environmental Management and Health, 11(1), 27-38.

Berrone, P. \& Gomez-Mejia, L.R. (2009). Environmental performance and executive compensation: an integrated agency-institutional perspective. Academy of Management Journal, 52(1), 103-126.

Boon, O.K., Arumugam, V. \& Hwa, T.S. (2005). Case studies: Does soft TQM predict employees' attitudes?. The TQM Magazine, 17(3), 279-289.

Bryman, A. \& Cramer, D. (1999). Quantitative data analysis with SPSS release 8 for Windows: a guide for social scientists, Routledge, London.

Chin, K.S. \& Pun, K.F. (1999). Factors influencing ISO 14000 implementation in printed circuit board manufacturing industry in Hong Kong. Journal of Environmental Planning \& Management, 42(1), 123-135.

Chinander, K. (2001). Aligning accountability and awareness for environmental performance in operations. Production and Operations Management, 10(3), 276-291.

Coakes, S.J. (2005). SPSS: analysis without anguish: version 12.0 for Windows, John Wiley $\&$ Sons Australia Ltd, Singapore.

Corbett, L.W. \& Cutler, D.J. (2000). Environmental management systems in the New Zealand plastics industry. International Journal of Operations \& Production Management, 20(2), 204-224.

Curkovic, S. (1998). Investigating the linkage between total quality management and environmentally responsible manufacturing. Unpublished dissertation, Western Michigan University, Kalamazoo, MI.

Daily, B.F., Bishop, J. \& Steiner R. (2007). The Mediating Role of EMS Teamwork as it pertains to HR Factors and Perceived Environmental Performance. Journal of Applied Business Research, 23(1), 95-109.

Daily, B.F., Bishop, J.W. \& Steiner, R. (2003). "The impact of human resource management practices on employee perceptions of environmental performance" in proceedings of National Decision Sciences Institute Conference Meeting, Washington D.C, United States.

Daily, B.F. \& Huang, S.C. (2001). Achieving sustainability through attention to human resource factors in environmental management. International Journal of Operations \& Production Management, 21(12), 1539-1552.

Dechant, K. \& Altman, B. (1994). Environmental leadership: from compliance to competitive 
advantage. Academy of Management Executive, 8(3), 7-20.

Denton, D.K. (1999). Employee involvement, pollution control and pieces to the puzzles, Environmental Management and Health. 10(2), 105-111.

Edgar, F. \& Geare A. (2005). HRM practice and employee attitudes: different measuresdifferent results. Personnel Review, 34(5), 534-549.

Eng, Q.E. \& Yusof, S.M. (2003). A survey of TQM practices in the Malaysian electrical and electronic industry. Total Quality Management, 14(1), 63-77.

Fernandez, E., Junquera, B. \& Ordiz, M. (2003). Organizational culture and human resources in the environmental issue: a review of the literature. International Journal of Human Resource Management, 14(4), 634-656.

Geralis, M. \& Terziovski, M. (2003). A quantitative analysis of the relationship between empowerment practices and service quality outcomes. Total Quality Management \& Business Excellence, 14(1), 45-62.

Govindarajulu, N. \& Daily, B.F. (2004). Motivating employees for environmental improvement. Industrial Management \& Data Systems, 104(4), 364-372.

Grandzol, J.R. \& Gershon, M. (1998). A survey instrument for standardizing TQM modeling research. International Journal of Quality Science, 3(1), 80-105.

Graves, B.A. (November 2003). ISO 14000: Environmental Management: What is it? What is required? Other company's experiences.... Products Finishing: pp.62-68.

Green, K.W., Wu, C., Whitten, D. \& Medlin, B. (2006). The impact of strategic human resource management on firm performance and HR professionals' work attitudes and work performance. International Journal of Human Resource Management, 17(4), 559-579.

Hair, J.F., Anderson, R.E., Tatham, R.L. \& Black, W.C. (1998). Multivariate data analysis. (5th ed.). Englewood Cliffs, NJ: Prentice-Hall International.

Hanna, M.D., Newman, W.R. and Johnson, P. (2000). Linking operational and environmental improvement through employee improvement, International Journal of Operations \& Production Management, 20(2), 148-165.

Herzberg, F. (1966). Work and the Nature of Man. (2nd ed.). Cleveland: World Publishing Company.

Igbaria, M. \& Guimaraes, T. (1993). Antecedents and Consequences of Job Satisfaction among Information Center Employees. Journal of Management Information Systems, 9(4), 145-174.

Iverson, R.D. \& Roy, P. (1994). A causal model of behavioral commitment: evidence from a study of Australian Blue-collar employees. Journal of Management, 20(1), 15-41.

Jaramillo, F., Mulki, J.P. \& Solomon, P. (2006). The role of ethical climate on salesperson's role stress, job attitudes, turnover intention, and job performance. Journal of Personal Selling 
\& Sales Management, XXVI(3), 271-282.

Jun, M., Cai, S. \& Shin, H. (2006). TQM practice in maquilodora: antecedents of employee satisfaction and loyalty. Journal of Operations Management, 24(6), 791-812.

Karia, N. \& Ahmad, Z.A. (2000). Quality practices that pay: empowerment and teamwork. Malaysian Management Review, 35(2), 66-76.

Karia, N. \& Asaari, M.H.A.H. (2006). The effects of total quality management practices on employees work-related attitudes. TQM Magazine, 18(1), 30-43.

Kaur, H. (2011). Impact of human resource factors on perceived environmental performance: an empirical analysis of a sample of ISO 14001 EMS companies in Malaysia. Journal of Sustainable Development, 4(1), 211-224.

Kitazawa, S. \& Sarkis, J. (2000). The relationship between ISO 14000 and continuous source reduction. International Journal of Operations \& Production Management, 20(2), 225-248.

Klassen, R.D. \& McLaughlin, C.P. (1993). TQM and Environmental Excellence in Manufacturing. Industrial Management \& Data Systems, 93(6), 14-22.

Lam, S.S.K. (1996). Total quality management and its impact on middle managers and front-line workers. Journal of Management Development, 15(7), 37-46.

Lam, S.S.K. (1995). Quality management and job satisfaction: an empirical study. International Journal of Quality \& Reliability Management, 12(4), 72-78.

Liang, C.T.H., Li, L.C. \& Kim, B.S.K. (2004). The Asian American Racism-related stress inventory: development, factor analysis, reliability and validity. Journal of Counseling Psychology, 51(1), 103-114.

Lok, P. \& Crawford, J. (2001). Antecendents of organizational commitment and the mediating role of job satisfaction. Journal of Managerial Psychology, 16(8), 594-613.

Mallak, L.A. \& Kurstedt, H.A. (1996). Understanding and using empowerment to change organizational culture. Industrial Management, 38(6), 8-10.

May, D.R. \& Flannery, B.L. (1995). Cutting waste with employee involvement teams. Business Horizons, 38(5), 28-38.

Morrow, D. \& Rondinelli, D. (2002). Adopting corporate environmental management systems: motivations and results of ISO 14001 and EMAS certification. European Management Journal, 20(2), 159-171.

Mowday, R.T., Steers, R.M. \& Porter, L.W. (1979). The measurement of organizational commitment. Journal of Vocational Behavior, 14(2), 224-247.

Nunnally, J.C. (1978). Psychometric Theory. (2nd ed.). New York: McGraw-Hill College.

O'hEocha, M. (2000). A study of the influence of company culture, communications, and employee attitudes on the use of 5Ss for environmental management at Cooke Brothers Ltd. 
The TQM Magazine, 12(5), 321-30.

Ooi, K.B., Arumugam, V., Teh, P.L. \& Chong, A.Y.L. (2008). TQM practices and its association with production workers. Industrial Management \& Data Systems, 108(7), 909-927.

Ooi, K.B., Bakar, N.A., Arumugam, V.V., Vellapan, L. \& Loke, A.K.Y. (2007). Does TQM influence employees' job satisfaction? An empirical case analysis. International Journal of Quality \& Reliability Management, 24(1), 62-77.

Pheng, L.S. \& May, C.F. (1997). Quality management systems: a study of authority and empowerment. Building Research and Information, 25(3), 158-169.

Porter, L.W., Steers, R.M., Mowday, R.T. \& Boulian, P.V. (1974). Organizational commitment, job satisfaction, and turnover among psychiatric technicians. Journal of Applied Psychology, 59(5), 603-609.

Pousette, A., Jacobsson, C., Thylefors, I. \& Hwang, C.P. (2003). The role of feedback in Swedish human service organizations. Community, Work \& Family, 6(3), 245-268.

Pun, K.F. \& Hui, I.K. (2001). An analytical hierarchy process assessment of the ISO 14001 environmental management systems. Integrated Manufacturing Systems, 12(5), 333-345.

Pun, K.F., Hui, I.K., Lau, H.C.W., Law, H.W. \& Lewis, W.G. (2002). Development of an EMS planning framework for environmental management practices. International Journal of Quality \& Reliability Management, 19(6), 688-709.

Quazi, H.A. (1999). Implementation of an Environmental Management System: the Experience of Companies Operating in Singapore. Industrial Management \& Data Systems, 99(7), 302-311.

Quazi, H.A., Khoo, Y.K., Tan C.M. \& Wong, P.H. (2001). Motivation for ISO 14000 certification: a development of a predictive model. Omega, 29(6), 525-542.

Rahman, S. \& Bullock, P. (2005). Soft TQM, hard TQM, and organizational performance relationships: an empirical investigation. Omega, 33(1), 73-83.

Ramus, C.A. (2001). Organizational support for employees: encouraging creative ideas for environmental sustainability. California Management Review, 43(3), 85-105.

Ramus, C.A. (2002). Encouraging innovative environmental actions: what companies and managers must do. Journal of World Business, 37(2), 151-164.

Ramus, C.A. \& Steger, U. (August 2000). The roles of the supervisory support behaviors and environmental policy in employee 'ecoinitiatives' at leading-edge European companies. Academy of Management Journal, 43(4), 605-26.

Remmen, A. \& Lorentzen B. (2000). Employee participation and cleaner technology: learning processes in environmental teams. Journal of Cleaner Production, 8(5), 365-373.

Rezaee, Z. \& Elam, R. (2000). Emerging ISO 14000 environmental standards: a step-by-step 
implementation guide. Managerial Auditing Journal, 15(1), 60-67.

Rifai, H.A. (2005). A test of the relationships among perceptions of justice, job satisfaction, affective commitment and organizational citizenship behavior. Gadjah Mada International Journal of Business, 7(2), 131-154.

Russo, M.V. \& Harrison, N.S. (2005). Organizational design and environmental performance: clues from the electronics industry. Academy of Management Journal, 48(4), 582-593.

Sammalisto, K. \& Brorson,T. (2006). Training and communication in the implementation of environmental management system (ISO 14001): a case study at the University of Gavle, Sweden, Journal of Cleaner Production, 14(1), 1-11.

Scott-Ladd, B., Travaglione, A. \& Marshall, V. (2006). Causal inferences between participation in decision making, task attributes, work effort, rewards, job satisfaction and commitment. Leadership\& Organization Development Journal, 27(5), 399-414.

Shrivastava, P. (1995). The role of corporations in achieving ecological sustainability. Academy of Management Review, 20(4), 936-960.

Silverman, S.B., Pogson, C.E. \& Cober, A.B. (2005). When employees at work don't get it: a model for enhancing individual employee change in response to performance feedback. Academy of Management Executive, 19(2), 135-147.

Steers, R.M. (1977). Antecedents and outcomes of organizational commitment. Administrative Science Quarterly, 22(1), 46-56.

Steers, R.M. \& Porter, L.W. (1991). Motivation and Work Behavior. (5th ed.). New York: McGraw-Hill.

Steelman, L.A. \& Rutkowski, K.A. (2004). Moderators of employee reactions to negative feedback. Journal of Managerial Psychology, 19(1), 6-18.

Strachan, P.A. (1997). Should environmental management standards be a mechanistic control system or a framework for learning?. The Learning Organization, 4(1), 10-17.

Strachan, P.A., Sinclair, I.M. \& Lal, D. (2003). Managing ISO 14001 implementation in the United Kingdom continental shelf (UKCS). Corporate Social Responsibility and Environmental Management, 10(1), 50-63.

Stone, L. (2000). When case studies are not enough: the influence of corporate culture and employee attitudes on the success of cleaner production and initiatives. Journal of Cleaner Production, 8(5), 353-359.

Tan, L.P. (2005). Implementing ISO 14001: is it beneficial for firms in newly industrialized Malaysia?. Journal of Cleaner Production, 13(4), 397-404.

Wee, Y.S. \& Quazi, H.A. (2005). Development and validation of critical factors of environmental management. Industrial Management \& Data Systems, 105(1), 96-114. 


\section{Macrothink}

Journal of Public Administration and Governance ISSN 2161-7104

Wilkinson, A. (1992). The other side of quality: 'soft' issues and human resource dimension. Total Quality Management, 3(3), 323-29.

Yukl, G.A. \& Becker, W.S. (2006). Effective empowerment in organizations. Organization Management Journal, 3(3), 210-231.

Zutshi, A. \& Sohal, A.S. (2004). Adoption and maintenance of environmental management systems: critical success factors. Management of Environmental Quality: An International Journal, 15(4), 399-419. 